\title{
Quality of Life Principles and Canadian Security Policy
}

\section{Catus Brooks*}

Department of Humanities, University of Victoria, British Columbia, Canada

\begin{abstract}
In the Canadian security policy domain, the political culture tends to be based on theories and practices that are potentially dangerous to Canadian overall health. There is a paradox in Canada, while Canadians have the "right to life" and most Canadians cherish universal healthcare, traditions of Canadian security policy can sometimes jeopardize Canadian overall health. We argue that Canadian security policymakers should prioritize quality of life principles and reconsider the undercurrents and assumptions of security policy that impact Canadian health. Therefore, our purpose is to question these normative traditions in Canadian security policy and offer the basics for a new security policy framework. Since first principles are the starting-point for any policymaking, as these principles are prior to action and are applicable across a variety of topics, this policy paper will introduce standards by which policymakers should proceed with security policies. Our intended audience is political scientists familiar with political thought and policy theory, so we get right to the point. We will not be defining every technical concept that arises, as we have omitted anything superfluous to our overall purpose. So, what security traditions put Canadian overall health at risk? What are the relationships between quality of life principles and security policy? What would a new security policy framework look like and how could it be implemented? These are the questions before me which we will explore, in order to open discussion on Canadian security policy and health.
\end{abstract}

Keywords: Humanity; Arts; Social

\section{Introduction}

To begin, we lay out the foundations for the security policy analysis at hand [1]. The forming of a public policy should begin with defining the problem [2]. The problem consists of a precise definition, recognition, an outline of their relationships, and their causality [2]. In order to perceive the problem, policymakers must recognize what exactly is wrong, which, in this instance, is the need for policymakers to identify the undercurrents of Canadian security policy [2]. To outline policy problem relationships, policymakers must connect the problem with predicaments that lie in differing policy domains ${ }^{1-4}$. Therefore, we relate traditions of security policy to Canadian health policy; ${ }^{5}$ we strictly focus on how the former impacts Canadian health. Lastly, causality refers to looking at the factors that led to the policy problem [2]. Hence, this essay specifically analyzes the undercurrents of Canadian security policy, which are the traditions that contradict Canadian health policy ${ }^{6}$. This accounts for the problem definition, which will ground the following discussion on security policy traditions.

\section{Review Strategies}

Next to underlying Canadian security policy are traditions dating from, at least, the $15^{\text {th }}$ century. One tradition under investigation

${ }^{1}$ Grant that the right to life means a high quality of life, coordinate with Canadian political culture around the cherishment of universal healthcare. See endnote 11 for further discussion on interpretations of life quality versus the preservation of life. Also note that we have omitted a discussion on the cherishment of healthcare in Canada.

${ }^{2}$ We have documented each significant omission as per endnotes.

${ }^{3} \mathrm{We}$ are not so much looking for complete answers, but instead interested in sparking a reflection from our audience.

${ }^{4}$ We have omitted a discussion on horizontal consistency (Pal, 2014).

${ }^{5}$ We do not discuss specific health policies, but rather how security policy relates to health factors.

${ }^{6}$ For the theoretical discussion and definition of horizontal consistency, see $\mathrm{Pa}$ (2014) pages $13-14,19$, and 34 . This concept we have omitted, as we have deemed our admissions more important to our overall argument. Nonetheless, what application the concept does have, is that it allows policymakers to check consistency within varying policy domains, here specifically health and security. is from Niccolo Machiavelli [3]. In chapter 17 of The Prince, he tries to validate the assumption that it is safe, in a prudential sense, for a ruler to be feared. Here he is sensitive to how fear may not necessarily lead to hatred. This idea is contestable however, for fear consistently results with hatred. More importantly, he does not acknowledge the inextricable relationship between fear policies and their negative health effects, fear and hatred having a terrible effect on citizen health. Intimidating citizens does not only impact their morale and mental health, it essentially renders them weak, less loyal, and less confident ${ }^{7}$. There is not much good in having fearsome leaders ruling over timid and dejected citizens. This is inherently a weak relationship, which spells inefficiency, resentment, and treachery. The problem with fear is not because it is misdirected, but because it is counter-productive ${ }^{8}$. Let the tradition of the use of fear in Canadian policy serve as a sample for the other contradictory traditions in Canadian security and health policy, for fear policies are not the only security policies that have negative health side-effects.

But just this tradition of fear policies in Canada raises an important question: is there a lack of maturity in Canadian security policies? Reading Machiavelli fairly, we must respect the tremendous impact of his policy philosophy on Canada, however the question still remains

${ }^{7}$ We have omitted specific examples of security policies that undermine Canadian health.

${ }^{8}$ By misdirection, we just mean that to use fear to stabilize a population, like preventing a riot or civil war, is, overall, not a wicked purpose. For more on the discussion regarding the use of fear and cruelty see Machiavelli (1994) chapters 8,17 , and 19

*Corresponding author: Catus Brooks, Professor, Department of Humanities, University of Victoria, British Columbia, Canada, Tel: 1-250-721-7211; E-mail: sirgraciousness@gmail.com

Received March 12, 2018; Accepted March 21, 2018; Published March 28, 2018

Citation: Brooks C (2018) Quality of Life Principles and Canadian Security Policy. Arts Social Sci J 9: 353. doi: 10.4172/2151-6200.1000353

Copyright: ( 2018 Brooks C. This is an open-access article distributed under the terms of the Creative Commons Attribution License, which permits unrestricted use, distribution, and reproduction in any medium, provided the original author and source are credited. 
if $15^{\text {th }}$ century fear strategies are imperfect. We argue that they indeed need to be updated and questioned. Canadian security governance is not a power game $[4]^{9}$. Canadian quality of life is a serious consideration, such that must not be compromised by ambitious pursuits of power. Traditionally, it may have been that politicians were judged by their ability and results ${ }^{10}$ But, specifically concerning security policies, politicians should be evaluated by how effective they can preserve their people's lives, which necessarily involves enhancing and protecting Canadian quality of life $[3,4]$. The purpose of security is to preserve people's lives, ${ }^{11}$ thus the evaluation of politicians must correspond with this purpose.

However, it is not enough to preserve people's lives in a minimal sense; that is, to leave citizens with a low quality of life. To prevent this shortfall, security policymakers should look to a number of life quality indicators. These include, the people's morale, physical constitution, mental health, mental stamina and stability, levels of happiness, and diseases and disorders as a result of fear ${ }^{12}$. Take the standard definitions for these terms. Clearly, if security is a matter of life and death, these factors cannot be ruled out of the equation [5]. For, without sufficient awareness of these factors, security policymakers could be leaving Canadian quality of life to a matter of chance. While these health considerations may not be indicators of immediate death, they may lead to death, and are, at the very least, indicators of a low quality of life.

But then the question arises, when must policymakers choose the option they deem the lessor of two evils? In the health and security context, this refers to policymakers perceiving security and health in such a way as to believe that security, at times, depends on compromising their people's health. Policymakers may not formulate such decision-making this way, but by putting the problem in these terms the issue becomes evident, that is the contradiction between security traditions and Canadian health. Nonetheless, we argue that this lessor of two evils dilemma can underlie what is known as the decision upon the exception, which is, in a way, securitization [6]. Here deciding upon the exception means deciphering the normal from the exception. Securitization means when elites decide what an emergency is; that is, when they declare that something is a security matter [7]. Policymakers might securitize a situation, compromise Canadian health, and believe that this securitization is the lessor of two evils. For instance, is it not at least plausible for a policymaker to sacrifice their citizens' health for state security? A critic might argue that state security is prior to Canadian health, as once security is established, citizen wellbeing will follow. However, policymaker should never, in principle, sacrifice one over the other, if it were possible to sacrifice neither.

${ }^{9}$ Note that Greene (1998) and Greene (2006) are not academic sources, however they are synthetic compilations of security traditions from the classical to the modern era, which underlie Canadian security studies and Canadian security policy.

${ }^{10}$ See Greene's (1998) preface for more on security traditions regarding politician and policy evaluation; particularly, his part on "[j]udge people by their actions" ( $p$. xix). Compare this bit with Machiavelli's (1994) chapters 6, 7,10, and 15 for the traditional context.

${ }^{11}$ For the discussion on security traditions regarding the preservation of life, contrast Aristotle (2009b) book 1, part 1-2, with Thomas Hobbes' (1651) chapters 14-16. According to Aristotle (2009b), the state's purpose is self-sufficiency in preserving human life, however the state's utmost end is to provide for the good life, which is a high life quality. In contrast, Hobbes' (1651) view on the purpose of the state is to strictly speaking, secure peace, even if such a peace does not provide for a high quality of life (p. 80).

${ }^{12}$ We have omitted definitions of the people's morale, physical constitution, mental health, mental stamina and stability, happiness levels, and diseases and disorders as a result of fear, as these terms are only ideas to keep in mind, not ideas that ou overall argument rests upon. With this list of health terms, just take their standard definitions, as we do not imply anything complicated.
We argue that policymakers should focus more on the rule than the exception. However, in all fairness, once policymakers get into action, they tend to get their hands dirty, rather than adhere to ideals [8]. The problem is that situations actually needing a sacrifice of Canadian health rarely occur and are usually the result of the government's own doing. Since these occasions are rare, security policymakers should treat them as such. Policymakers must not be preoccupied with the possibility of these emergencies occurring, building a regime on these presuppositions, ${ }^{13}$ and then ultimately creating situations ${ }^{14}$ where the lessor of two evils dilemma is plausible, claiming a situation to be the exception. Problems of prudence and emergency-creation follow in this essay's policy implementation bit.

Moreover, the relationships between security policy traditions and health policy should be approached with Michael Foucault's bio politics and govern mentality. In this essay, his concept govern mentality refers to the outcome of a multitude of thoughts and practices that shape assumptions about how government should be exercised [9]. Security policy traditions that contradict Canadian health are exactly these kinds of assumptions. These norms are not only preconceptions and assertions, they are undercurrents influencing the execution and organization of government. Bio politics and govern mentality relate power, knowledge, and the importance of citizen health, understanding the dynamic and inextricable connections between these three factors. Thus, Foucault allows policymakers to consider health's power dynamics, which are influenced by assumptions and undercurrents in security policy.

Next, we will introduce the beginnings to a security policy framework and outline how to proceed with policy implementation. In this context, a policy framework is a guide for making future actions and decisions in Canadian security, with respect to its implications for Canadian health [2]. Moreover, the elementary principle for a Canadian security policy framework is the prioritization of Canadian quality of life and health, as the preservation and enhancement of life is the purpose of security. This principle must be the essence and impetus behind security policies. By starting with this prioritization in mind, policymakers can structure their future actions and decisions, ${ }^{15}$ rather than ignore Canadian quality of life, leaving the health aspects of future security policies to chance [4]. We reject that Canadian security depends on the pressures of the situation, ${ }^{16}$ and believe that the future is more due to voluntary agency than involuntary structural constraints [10]. Prudence does not necessarily mean to be adaptable,$^{17}$ which could lead to conforming to lower standards, rather it should mean to

${ }^{13} \mathrm{We}$ have omitted elaboration on security policymakers assuming the security presuppositions under investigation.

${ }^{14} \mathrm{We}$ have omitted how security policymakers may self-create negative situations where their regime is more applicable.

${ }^{15}$ Thucydides once wrote, "[i]t is a common mistake ... to begin at the wrong end to act first and to wait for disaster to discuss the matter" (Greene, 2006, p. 164) For a greater discussion on the traditions of planning in security studies, see both Greene (1998) Ch. 28 and Greene (2006) Ch. 12.

${ }^{16}$ Note that we use the term pressure, to add force to the idiom the times. The point here relates to the discussions regarding Machiavelli's (1994) Ch. 25 and Greene's (2006) Ch. 2. Both authors discuss, in greater length, the security norms regarding changing to the spirit of the times and adapting to the situation; actually, Greene (2006), in Ch. 2, uses some of the exact same expressions as Machiavelli (1994), Ch. 25. Nonetheless, we argue for a more principled approach to security with respect to quality of life.

'7here we are referring to Greene's (2006) discussion in Ch. 2, regarding security formulae and the reexamination of principles and beliefs for adaptability (p. 15-26). Note that we are bringing his ideas regarding planning from Greene (1998) Ch. 28 and Greene (2006) Ch. 12 together with Greene (2006) Ch. 2 to demonstrate that these chapters can contradict each other. Ultimately, the prioritization of planning with quality of life principles comes before adaptability. 
create the state's own future, by means of preparation and clear goal setting. In developing more guidelines, as they will be context specific, security policymakers must see that Canadian quality of life comes before adaptability [11-13].

Lastly, we will try to work out the basics for security policy implementation in the short time we have here. Policy implementation is the delivery and organizing of outcomes, through specific means and techniques [2]. This organizing and delivering should be driven by the prioritization of Canadian quality of life. The standards are then clear, policy implementation must account for the rule, which is the prioritization of Canadian health and quality of life in security policy, over the exception, which we have questioned the applicability [2]. Perhaps the best insight on how to implement health and quality of life principles is to evaluate past security policies [2] ${ }^{18}$. This would allow one to determine how high these principles were prioritized, what their effects were, and how to adapt these past policies to higher quality of life standards. Though the length of our discussion so far does not suit the seriousness of the topics we have proposed, as these topics deserve much more elaboration, we have at least made clear the first principle for security policies.

\section{Conclusion and Discussion}

We have posed the question regarding what security policy traditions contradict Canadian quality of life, because an answer is needed due to differing opinions. Meaning, we disagreed with ignoring or under-valuing quality of life principles in security policy formulation. Security policy should not be motivated by fear tactics or preoccupied with trying to decide on the exception; quite simply it is about effectively preserving Canadian life. Security policy is a grave matter and security policymakers should not be valued by how to make the best out of a bad situation, but rather how great they are at creating a

${ }^{18} \mathrm{We}$ have omitted past practices in Canada that should be reevaluated. safe and healthy future for Canadians. Thus, we have put security policy implementation in outline. Though we cannot expect anyone to know exactly how to implement a security policy from the mere discussion of this essay, this only necessitates future investigation on security policy implementation, sensitive to Canadian health and quality of life.

\section{References}

1. Government of Canada (2017) Constitution Act 1982.

2. Pal L (2014) Beyond Policy Analysis: Public Issue Management in Turbulent Times. Toronto, ON: Nelson Education Ltd.

3. Machiavelli N (1994) Selected Political Writings: The Prince, Selections from the Discourses and Letter to Vettori. Indianapolis IN: Hacket Publishing Company Inc.

4. Greene R (1998) The 48 Laws of Power. New York, NY: Penguin Group Inc.

5. Sun-Tzu (2003) The ART of WAR: The essential translation of the classic book of life. New York NY: Penguin Group.

6. Schmitt C (2007) The Concept of the Political: Expanded Edition. Chicago IL: The University of Chicago Press.

7. Piché G, Salter M (2011) The Securitization of the US-Canada Border in American Political Discourse. Canadian Journal of Political Science 44: 929-951.

8. Behr H (2013) Common sense', Thomas Reid and realist epistemology in Hans J Morgenthau. International Politics 50: 753-767.

9. Murray K (2007) Governmentality and the Shifting Winds of Policy Studies. In: Orsini M, Smith M (eds.) Critical Policy Studies, Vancouver BC: UBC Press, pp: 161-184.

10. Aristotle (2009a) Nicomachean Ethics (W Ross Trans).

11. Aristotle (2009b) Politics (W Ross Trans).

12. Greene R (2006) The 33 Strategies of War. New York, NY: Penguin Group Inc.

13. Hobbes T (1651) Leviathan or the Matter, Forme and Power of a Commonwealth Ecclesiasticall and Civill. London, EN: St. Pauls Church-yard. 